Results: 4 of the 6 papers included in this review reported improvements in pain ranging from 30 to $83 \%$ and in functional status ranging from 26 to $86 \%$ from the pre-injection state, with follow-up periods lasting up to 2 years after the EI. 2 of these 4 studies showed Level II evidence for El for long-term efficacy in managing chronic sciatica, with no significant difference among CEI, IEI or TEI.

The remaining 2 papers (out of the total 6) associated El with immediate improvements in both pain and function, but found the benefits to be unsustained. 1 paper reported 1 serious adverse event in one of the trials analyzed and found the data on harms to be sparse on most trials. Another paper concluded that injecting local anesthetic alone might be preferable to injecting local anesthetic with steroid as omitting the steroid could lessen the risk of rare, but possibly fatal complications.

Conclusions: Despite variability in the studies included and methods used for data synthesis, most of the articles included in this review showed positive results for both pain relief and improvement in functional status with El.

Although no studies found significant difference among CEI, IEI or TEl in terms of efficacy, each approach has its advantages and these should be taken into account when choosing the best approach for each patient.

As supporting evidence, this review shows that El with or without steroids are a fast, safe and clinically effective treatment method for patients with chronic sciatica.

References:

[1] Bhatti A, Kim S. Role of Epidural Injections to Prevent Surgical Intervention in Patients with Chronic Sciatica: A Systematic Review and Meta-Analysis. Cureus. 2016, 8(8): e723.

[2] Pinto R, et al. Epidural Corticosteroid Injections in the Management of Sciatica: A Systematic Review and Meta-analysis. Ann Intern Med. 2012, 157:865-877. Disclosure of Interest: None declared

DOI: 10.1136/annrheumdis-2017-eular.2747

\section{AB0936 FLEXIBILITY AND STRENGTH OF THE TRUNK IN CHRONIC LOW BACK PAIN TWO YEARS AFTER A FUNCTIONAL RESTORATION PROGRAM}

R. Maaoui ${ }^{1}{ }^{11}$, S. Zrida ${ }^{1}$, I. Ksibi ${ }^{1}$, N. Mouhli ${ }^{1}$, H. Rahali ${ }^{1}$, M. Sghir $^{2}$, W. Kossomtini ${ }^{2} .{ }^{1}$ Physical and Rehabilitation Medicine, military hospital Tunis, tunis, ${ }^{2}$ Physical and Rehabilitation Medicine, regional hospital Tahar Sfar of Mahdia, Mahdia, Tunisia

Background: Low-back pain affects significatively the flexibility and the muscular strength of the trunk. It was demonstrated in literature the positive effect of restoration programs in these parameters at short-term evaluation.

Objectives: Evaluate the flexibility and the muscular strength and endurance of the trunk two years after a functional restoration program

Methods: Prospective study on patients with low back pain evaluated before, at the end of the restoration program and two years later. We have evaluated the following parameters: trunk flexibility by use of the Schöber index and the finger-ground distance test (FGD), hamstring flexibility by measurement of the thigh-leg (TL) angle, back flexor and back extensor endurance, assessed with the Shirado test and the Sorensen test, respectively.

Results: Thirty patients were evaluated. Initially, the results reported decreased flexibility: $53 \%$ with $\mathrm{FGD}>15.53 \mathrm{~cm} ; 37 \%$ with the thigh-leg (TL) angle $>15^{\circ}$ and decreased muscle endurance: Schirado 30.26 $\pm 29.662 \mathrm{~s}$; Sorensen $26.3860 \pm 18.5208 \mathrm{~s}$. The short-term efficacy of the program showed significatively improvement in all parameters $(p=0,01)$. However, this improvement decreased 2 years later but it remains significant. This loss can be attributed to the fact that $70 \%$ of patients abandoned self-rehabilitation exercises

Conclusions: The restoration program seems to have good effect in short and long term evaluations in the flexibility and muscular strength of the trunk.

Disclosure of Interest: None declared

DOI: 10.1136/annrheumdis-2017-eular.4954

\section{AB0937 DUPUYTREN'S CONTRACTURE: 15 YEARS OF EXPERIENCE WITH 36 CASES}

H. Mouanaa, M. Jguirim, A. Arfa, A. Farhat, M. Brahim, A. Mhenni, Z. Saoussen, I. Bejia, M. Touzi, N. Bergaoui. Rheumatology Unit of the Monastir University Hospital, Monastir, Tunisia

Background: Dupuytren's contracture is characterized by thickening and retraction of the palmar aponeurosis due to fibroblastic proliferation leading to progressive and irreducible fingers' flexion. Dupuytren's contracture appears to be a disease with poor clinical symptomatology and the therapeutic progress, in particular the needle aponeurotomy, continues to increase.

Objectives: We propose to describe the epidemiological, clinical and therapeutic characteristics- particularly the needle fasciotomy- of Dupuytren's contracture diagnosed and treated in our Rheumatology department.

Methods: This is a retrospective descriptive study that collected patients with Dupuytren's disease over a 15-year period from 2001 to 2016.

Results: Thirty-six patients were collected. The mean age was $63 \pm 10$ years (46 years, 83 years) and the sex ratio was $5.34 \%$ of the patients were manual workers, of whom $42 \%$ were masons, $25 \%$ were farmers and $17 \%$ were carpenters. $8 \%$ Of longshoremen and $8 \%$ of dressmakers. The personal history was diabetes in
$63 \%$ of cases, of which $26 \%$ were unbalanced, hypertension in $31 \%$ of cases and hypercholesterolemia in $14 \%$ of cases. $6 \%$ of patients were epileptic. $23 \%$ of patients were ethyl and $13 \%$ were smokers. $6 \%$ had an associated Leddherhose disease. $9 \%$ of our patients had a family history of Dupuytren's disease. The mean time to diagnosis was 60 months [03 months to 180 months]. The clinical examination showed an exclusive involvement of the left hand in $22 \%$ of cases, right hand in $12 \%$ of cases and bilateral involvement in $66 \%$ of cases. The fingers affected were: $59 \%$ the ring finger, $49 \%$ the little finger, $23 \%$ the middle finger, $12 \%$ the index and $5.5 \%$ the inch, in order of frequency of mention. The stages of Dupuytren's disease at their discovery were as follows: stage $4(25 \%)$, stage $3(34 \%)$, stage $2(24 \%)$ and stage $1(17 \%)$. Skin examination showed that $58 \%$ of the skin was inflicted and $42 \%$ of the skin was soft. From a therapeutic point of view, $86 \%$ of the patients benefited from a needle aponevrotomy with a good progression in $97 \%$ and a recurrence in $8 \%$ of the cases. In all stages combined, the average postoperative therapeutic gain was 0.83 stage at the Left hand and 1.43 stage at the right.

Conclusions: The Dupuytren's contracture is the object of a scientific subject whose wealth grows exponentially. These range from the paternity of his first description, to the place of the last therapeutic modalities.

Disclosure of Interest: None declared

DOI: 10.1136/annrheumdis-2017-eular.6967

\section{AB0938 AN ATYPICAL CASE OF SARCOIDOSIS REVEALED BY A BILATERAL PREPATELLAR BURSITIS}

${ }^{\text {J. Perrier-Cornet }}{ }^{1}$, R. Ouichka ${ }^{1}$, S. Moawad ${ }^{2}$, I. Chary-Valckenaere ${ }^{1}$.

${ }^{1}$ Rheumatology; ${ }^{2}$ Dermatology, CHU Nancy, NANCY, France

Background: Prepatellar bursitis is not very frequent in daily practice and the main causes are infections, crystal arthropathies or trauma.

We report the case of a 49-year-old man presented to our department with bilateral anterior knee pain. Pain started 3 months ago without any triggering factor. He denied any trauma or infection. The patient also denied any history of gout, rheumatoid arthritis or systemic lupus.

Objectives: On clinical exam, bilateral knee swellings were noticed consistent with prepatellar bursitis with no wound or abrasion, no fever, signs of arthritis or lymphadenopathy.

Methods: Knee ultrasonography and skeletal scintigraphy confirmed symmetrical prepatellar bursitis. Laboratory findings showed elevated ESR and CRP but no other abnormalities.

Few days later, the patient presented with subcutaneous painful nodules that appeared on his forearms. Biopsy was done and showed deep subcutaneous sarcoid nodules of Darier-Roussy, confirming the diagnosis of sarcoidosis.

Further work up revealed typical sarcoid pulmonary involvement. Bilateral hilar and mediastinal lymphadenopathy with beaded appearance of interlobular septa were noticed on CT-scan of the chest.

The Positron Emission Tomography showed abnormally high ${ }^{18} \mathrm{~F}$-fluorodeoxy glucose uptake in the thoracic lymph nodes.

Results: All the diagnostic work up confirmed the diagnosis of systemic sarcoidosis. The decision was to start oral corticosteroids. Few days after starting the systemic steroids, the skin lesions and the knees pain improved significantly. Conclusions: The conclusion is that after excluding the main causes of bursitis (infection, trauma and inflammatory arthritis) (1), it's necessary to keep in mind sarcoidosis as possible diagnosis.

This clinical observation is important because involvement of the bursa is a rare musculoskeletal manifestation of sarcoidosis (2). Moreover, it's very uncommon to diagnose sarcoidosis presenting with just bilateral prepatellar bursitis with no other musculoskeletal or rheumatological symptoms (3).

The association of bursitis, inflammatory skin lesions and thoracic lymphadenopathy is uncommon but may suggest the diagnostic of sarcoidosis.

\section{References:}

[1] Mathieu S, Prati C, Bossert M, Toussirot E, Valnet M, Wendling D. Acute prepatellar and olecranon bursitis. Retrospective observational study in 46 patients. Joint Bone Spine. 2011;7:423-4.

[2] Fujimoto H, Shimofusa R, Shimoyama K, Nagashima R, Eguchi M. Sarcoidosis presenting as prepatellar bursitis. Skeletal Radiol. 2006;35:58-60.

[3] Ruangchaijatuporn T, Chang EY, Chung CB. Solitary subcutaneous sarcoidosis with massive chronic prepatellar bursal involvement. Skeletal Radiol. 2016;45:1741-5.

Disclosure of Interest: None declared

DOI: 10.1136/annrheumdis-2017-eular.2753

\section{AB0939 CHANGE IN THE SURGICAL TREATMENT FOR CERVICAL SPINE DISORDERS RELATED TO RHEUMATOID ARTHRITIS DURING RECENT 15 DECADES}

K. Sakuraba, K. Kai, H. Miyahara. National Hospital Organization Kyushu Medical Center, Fukuoka, Japan

Background: Since the appearance of biological DMARDs in Japan, disease control of rheumatoid arthritis has been ameliorated. Inflamed synovitis and destructive arthritis declined dramatically, which resulted in a decrease in the number of synovectomy and joint prosthesis gradually. On the other hand, 
surgeries for hand or foot disorders have been increasing. However, it is unclear about the surgery for cervical spine disorder.

Objectives: We clarified the change in the surgical treatments for cervical spine disorder related to RA patients at our institution.

Methods: From 2001 to 2015 , we identified 71 RA patients with a cervical spine surgery. The mean age was 65.4 years (range, 44-90 years). The patients consisted 11 males and 60 females. The mean disease duration was 20 years (range, 0-52 years). They were classified into three subgroups according to the affected level: the upper lesions (UL) such as atlantoaxial subluxation, the middle and lower lesions (MLL) including subaxial subluxation, and the expanded lesions (EL) which have both features. Individual groups were assessed the change of the number of surgical treatment. In addition, we divided the period into first seven years (from 2001 to 2007) and last eight years (from 2008 to 2015), and compared each other.

Results: There were 38 patients in UL, 25 patients in MLL and 8 patients in EL. Most patients in UL were underwent atlantoaxial fixation by Magerl and Brooks procedure, and the number of them was constant throughout the entire period. Occipito-cervical fusion has been decreasing. Although there were much surgeries of MLL disorder in last 8 years than that in first 7 years, most of them did not have RA change such as endplate erosion and subluxation.

Conclusions: There was no significant change in EL throughout all periods. In conclusion, surgeries for cervical spine disorder of RA patients remained in our institute. However, disorders related to RA within them, especially MLL, were decreasing. it indicates that expansion of RA remission has led to the reduction of cervical spine surgeries with RA change.

Disclosure of Interest: None declared

DOI: 10.1136/annrheumdis-2017-eular.1156

\section{AB0940 EFFICACY AND SAFETY OF PLATELET RICH PLASMA PERI-NEURAL INJECTION IN TREATMENT OF DIABETIC NEUROPATHY: DOUBLE BLIND RANDOMIZED CONTROLLED TRIAL}

M. Hassanien ${ }^{1}$, Y. Saad ${ }^{1}$, A. Alawamy ${ }^{2}$, W.A. Khalifa ${ }^{3}$, D. Abdelkarem ${ }^{4}$. ${ }^{1}$ Rheumatology Department; ${ }^{2}$ Anathesia department Assuit university; ${ }^{3}$ Internal Medicine; ${ }^{4}$ Clinical Pathology, Assuit University, assuit, Egypt

Background: Neuropathy is a common complication of diabetes mellitus (DM) not only leads to an impaired quality of life, but also to an increased morbidity and mortality.Autologous platelet-rich plasma is easy and cost-effective method. Platelet-derived angiogenesis factor capable of stimulating new capillary growth by inducing migration of endothelial cells, influence the process of angiogenesis and revascularisation.

Objectives: evaluate the clinical efficacy and safety of perineural PRP injection in the treatment of diabetic neuropathy (DN) compared to tradition medical treatment.

Methods: Sixty patients were selected from Endocrinology unit Department of Internal medicine, Assuit university Hospital, Egypt had type II diabetes mellitus neuropathy (DN) of at least 5 years duration of symptoms, regardless of age and gender double blindly divided into two groups, both groups had control blood glucose. Group I underwent PRP preineural injection under ultrasound guidance and group II underwent medical treatment. Baseline pain and nerve conduction study of upper and lower limb nerves and sural nerve conduction studies, F-wave. nerve conduction study were determined at 3 months after the procedure. Primary outcome was the total effective rate. The total effective rate $=$ (the number of patients with significant effect+ the number of patients with effect)/total number of patients. A "significant effect" meant that limb pain, numbness, and fatigue were significantly reduced, nighttime sleep was improved, and NCV from electromyography increased $>5 \mathrm{~m} / \mathrm{s}$ or returned to normal. An "effect" meant that the symptoms mentioned above were relieved, and NCV compared with pre-treatment increased $<5 \mathrm{~m} / \mathrm{s}$. "Failure" meant that the symptoms did not improve, and there were no changes in NCV electromyography

Results: We recruited 60 diabetic patients (type II) with peripheral neuropathy with a mean age $35.27 \pm 12.86$ years with disease duration of $7.42 \pm 3.51$ years. Of these, $56 \%$ cases with upper limb nerves neuropathy only while the rest $44 \%$ had sural nerve plus upper limb nerves neuropathy. Nerve conduction study showed axonal affection in only $26 \%$ and all had delayed distal latency and prolonged motor conduction velocities. generalized DN is found in $70 \%$ of total patients and $30 \%$ of had focal Entrapment of the nerve includes median neuropathy at the wrist $50 \%$, ulnar neuropathy at the elbow $30 \%$ and peroneal neuropathy at the knee $20 \%$ and no patients had radiculoplexus neuropathies.

\begin{tabular}{|c|c|c|c|}
\hline & \multicolumn{2}{|c|}{ Group I } & \multirow[t]{2}{*}{ P-value } \\
\hline & Baseline & 3 months Post injection & \\
\hline Mean motor NCV $\pm S D$ & $35.6 \pm 12.67$ & $46.38 \pm 10.68$ & $\leq 0.05^{\star}$ \\
\hline Mean $\mathrm{DL} \pm \mathrm{SD}$ & $9.19 \pm 8.16$ & $4.55 \pm 5.66$ & 0.09 \\
\hline \multirow[t]{2}{*}{ Sural conduction velocity } & $17.00 \pm 10.86$ & $34.00 \pm 6.84$ & $\leq 0.001^{\star \star}$ \\
\hline & Group I & Group II & $\mathrm{P}$-value \\
\hline Effect & $85.47 \pm 9.91 \%$ & $79.38 \pm 12.40 \%$ & 0.16 \\
\hline Significant effect & $95.29 \pm 15.28 \%$ & $81.00 \pm 9.64 \%$ & $\leq 0.001^{\star \star}$ \\
\hline Total effective rate & 22/30 (73.3\%) & $11 / 30(36.6 \%)$ & $\leq 0.05^{\star}$ \\
\hline Failure & $7.00 \pm 2.86 / 30$ & $18.00 \pm 2.84 / 30$ & $\leq 0.001^{\star \star}$ \\
\hline
\end{tabular}

Conclusions: Autologous platelet-rich plasma is an easy and cost-effective method as a treatment of diabetic peripheral neuropathy.

Disclosure of Interest: None declared

DOI: 10.1136/annrheumdis-2017-eular.1272

\section{AB0941 PATIENTS PROFILE AT ORTHOGERIATRIC UNIT: NEW MODEL OF CARE}

S. Hammami, A. Meziani, A. Ioana, C. Dumont, V. Latteur. Geriatric, GHdC Belgium, Charleroi, Belgium

Background: Fractures in elderly patients its a prevalent problem. Older patients due their characteristics requires a specific care. The orthogeriatric Unit has been shown to be one of the most beneficial units. It is important to evaluate the model of care

Objectives: Evaluate the main variables of fractures patients treated at a orthogeriatric Unit and their complications

Methods: This is a partially concurrent prospective study, taking place in a large urban academic hospital GHdC in Belgium. The participants were 87 consecutive elderly people, admitted directly to a geriatric-based orthogeriatric ward.

Results: A total of 87 patients were included. The average age was $85.2 \pm 5.2$ years, 20 male, 67 female. Most of them $(n=44,52 \%)$ were admitted for a hip fractures, $44 \%(n=38)$ were transferred from emergency department, ISAR score was $3.9 \pm 1.1$, Preoperative stay was less than $24 \mathrm{~h}$ for $54 \%$ of our population, Mini nutritional assessment was $18.7 \pm 4.3$, Mini mental state examination was 20.6 \pm 6.4 , the Cumulative IIIness Rating Scale was $17.1 \pm 4.5$, the mean number of medicine was $6.8 \pm 3.3$, Activity of Daily Living 15 days after admission was 12.2 \pm 5.5 . Delirium was the principal complication $55 \%(n=44)$. Mean hospital stay between admission and discharge/transfer to convalescence unit was $23.8 \pm 12.9$. In-hospital mortality was $11 \%(\mathrm{n}=10)$

Conclusions: Fractures is a frequent and disabling pathology among geriatric fragile population, its treatment requires an interdisciplinary approach. This must be managed by the collaboration between geriatrician and orthopedist. We believe that the orthogeriatric Unit providing subacute and acute care will improve the general outcome of fragile geriatric patients

References:

[1] González-Montalvo Jl et al The orthogeriatric unit for acute patients: a new model of care that improves efficiency in the management of patients with hip fracture. Hip Int. 2010 Apr-Jun;20(2):229-35.

[2] Smith TO et al Factors predicting incidence of post-operative delirium in older people following hip fracture surgery: a systematic review and meta-analysis. Int J Geriatr Psychiatry. 2017 Jan 17.

Acknowledgements: Geriatric multidisciplinary team working in GHdC Charleroi Belgium.

Disclosure of Interest: None declared

DOI: 10.1136/annrheumdis-2017-eular.5845

\section{AB0942 EFFECT OF CORTICOSTEROID INFILTRATIONS ON DIABETES. A MONOCENTRIC RETROSPECTIVE STUDY}

S. Mathieu, M. Couderc, Z. Tatar, J. Lopez, S. Malochet-Guinamand,

J.-J. Dubost, A. Tournadre, M. Soubrier. Rheumatology, CHU Gabriel Montpied, Clermont-Ferrand, France

Background: Corticosteroid therapy can unbalance diabetes, particularly when administered orally, but also during articular infiltration. Corticosteroid infiltrations are an integral part of the therapeutic arsenal in rheumatology. They are utilized to treat congestive articular flare-ups of osteoarthritis or inflammatory rheumatic diseases. Periarticular or ductal pathologies, such as trochanteric bursitis, rotator cuff pathology and carpal-tunnel syndrome, may require the use of these infiltrations. Caution is often required when using corticosteroid infiltrations in diabetics.

Objectives: The purpose of our study was to evaluate whether or not diabetic patients undergoing a corticosteroid infiltration during hospitalization had a diabetes imbalance.

Methods: Diabetic patients having undergone a corticosteroid infiltration during hospitalization between 2009 and 2015 were sought. We collected data regarding their rheumatological pathology, glycated hemoglobin $(\mathrm{HbA} 1 \mathrm{c})$, and fasting glycemia on the day of the infiltration, the next day and after 48 hours.

Results: A total of 114 patients were included in our study. The average age was $72.1 \pm 9.4$ years. All of them had Type 2 diabetes, and 35 of them were treated with insulin. Average $\mathrm{HbA} 1 \mathrm{c}$ was $7.3 \pm 0.1 \%$. Overall, $47(41.2 \%)$ patients had an $\mathrm{HbA} 1 \mathrm{c}$ below $7 \%$. A total of $31(27.2 \%)$ patients had a diabetes imbalance after infiltration, and 19 of these, who were taking oral antidiabetics, required 48 hours of rapid insulin to balance their glycemia. Overall, 12 patients increased their insulin dose. Out of the 47 patients with good HbA1c, 7 (14.9\%) of them had a glycemia imbalance, versus $24(35.8 \%)$ who were unbalanced out of the 67 patients whose $\mathrm{HbA1c}$ exceeded $7 \%(\mathrm{p}=0.013)$.

Conclusions: Corticosteroid infiltrations can lead to a diabetes imbalance, thus making it necessary to administer a few days of rapid insulin or to increase the insulin dose. A patient whose $\mathrm{HbA1c}$ is below $7 \%$ has a low risk of unbalancing his/her diabetes after corticosteroid infiltration.

Disclosure of Interest: None declared 